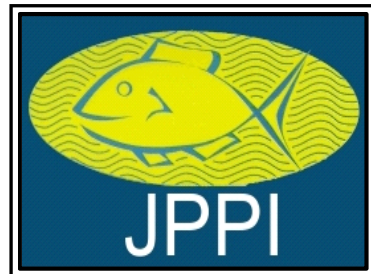

Tersedia online di: http://ejournal-balitbang.kkp.go.id/index.php/jppi

e-mail:jppi.puslitbangkan@gmail.com

JURNAL PENELITIAN PERIKANANINDONESIA

Volume 23 Nomor 1 Maret 2017

p-ISSN: 0853-5884

e-ISSN: 2502-6542

Nomor Akreditasi: 653/AU3/P2MI-LIPI/07/2015

\title{
ANALISIS PRODUKTIVITAS DAN SUSEPTIBILITAS PADA TUNA NERITIK DI PERAIRAN PELABUHANRATU
}

\section{PRODUCTIVITY AND SUSCEPTIBILITY ANALYSIS FOR THE NERITIC TUNA IN THE WATERS OF PALABUHANRATU}

\author{
Eva Suryaman ${ }^{\star 1}$, Mennofatria Boer ${ }^{2}$, Luky Adrianto² dan Lilis Sadiyah² \\ ${ }^{1}$ Program Studi Pengelolaan Sumberdaya Pesisir dan Lautan, Sekolah Pascasarjana, IPB. \\ Jl. Agatis, Bogor-16680, Jawa Barat, Indonesia \\ ${ }^{2}$ Departemen Manajemen Sumberdaya Perairan, Fakultas Perikanan dan IImu Kelautan, IPB. \\ Jl. Agatis, Bogor-16680, Jawa Barat, Indonesia \\ ${ }^{3}$ Badan Penelitian dan Pengembangan Kelautan dan Perikanan, JI. Pasir Putih II, Ancol Timur Jakarta \\ Utara-14430, Jakarta, Indonesia \\ Teregistrasi I tanggal: 09 Maret 2017; Diterima setelah perbaikan tanggal: 24 Maret 2017; \\ Disetujui terbit tanggal: 04 April 2017
}

\begin{abstract}
ABSTRAK
Pada perikanan tuna, tuna neritik merupakan kelompok ikan yang dominan tertangkap pada perikanan pantai, termasuk perikanan skala kecil dan bersifat artisanal. Penangkapan ikan tuna neritik di perairan Palabuhanratu yang semakin intensif setiap tahunnya tanpa didasari pengelolaan yang tepat, diduga akan mengakibatkan terjadinya penurunan stok sumberdaya ikan. Penelitian ini bertujuan untuk menganalisa keberlanjutan spesies neritik tuna menggunakan analisis produktivitas dan suseptibilitas / Productivity and Susceptibility Analysis (PSA). Penelitian ini dilaksanakan dari Februari hingga Mei 2016 di perairan Palabuhanratu. Hasil penelitian menunjukan nilai kerentanan tuna neritik berturut-turut untuk ikan tenggiri 1.25, tongkol krai 1.37, tongkol abu-abu 0.91 , tongkol komo 1.49 , dan tongkol lisong 1.41. Hal ini menunjukan bahwa tingkat kerentanan ikan tuna neritik terhadap overfishing saat ini masih rendah karena nilainya masih dibawah 1,8, sehingga aktivitas penangkapan masih dapat ditingkatkan terutama untuk ikan tenggiri dan tongkol abu-abu yang memiliki kerentanan terendah.
\end{abstract}

Kata Kunci: Analisa produktivitas dan suseptibilitas; Palabuhanratu; tuna neritik; tingkat kerentanan

\begin{abstract}
Neritic tuna are mainly caught by coastal fisheries, including small scale fisheries and artisanal fisheries. The continuous absence of proper management for neritic tuna, will result in a decline in the stock of fish. This study aims to analyze the sustainability of neritic tuna species by analyzing the productivity and susceptibility (PSA). The research was conducted from February to May 2016 in Palabuhanratu waters. Vulnerability indexs for narrow-barred Spanish mackerel (Scomberomorus commerson) 1.25, frigate tuna (Auxis thazard) 1.37, longtail tuna (Thunnus tonggol) 0.91, kawakawa (Euthynnus affinis) 1.49, and bullet tuna (Auxis rochei) 1.41. These vulnerability indexs shows that level of vulnerability for overfishing for neritic tuna is low because the vulnerability index still below the maximum limit vulnerability index (1.8), fishing activities can still be increased, particularly for narrowbarred Spanish mackerel and longtail tuna that has the lowest vurnerability.
\end{abstract}

Keywords: Neritic tuna; Palabuhanratu water; productivity and susceptibility analysis; vulnerability index

\section{PENDAHULUAN}

Tuna neritik merupakan kelompok tuna yang dominan tertangkap pada tipe perikanan pantai (coastal fisheries) dan tergolong perikanan skala kecil (small scale fisheries) (Naderi, 2016). Berdasarkan Keputusan Menteri Kelautan dan Perikanan Nomor 107/2015 Tanggal 28 Agustus 2015 tentang RPP TCT

Korespondensi penulis:

e-mail: eva_suryaman@yahoo.com 
(Rencana Pengelolaan Perikanan Tuna Cakalang dan Tongkol), tongkol (neritic tuna) yang dikelola dalam RPP TCT terdiri dari 4 (empat) jenis tongkol (neritic tuna) dan 2 (dua) jenis tenggiri (sheer-fish). Jenis tongkol meliputi lisong (Auxis rochei), tongkol krai (Auxis thazard), tongkol komo (Euthynnus affinis) dan tongkol abu-abu (Thunnus tonggol) sementara sheer fish mencakup tenggiri papan (Scomberomorus guttatus) dan tenggiri (Scomberomorus commerson).

Samudera Hindia bagian timur merupakan salah satu perairan produktif bagi kegiatan penangkapan ikan tuna neritik di perairan Indonesia. Hasil tangkapan tuna tersebut didaratkan di pelabuhan perikanan seperti Palabuhanratu, Cilacap, dan Prigi. Palabuhanratu sebagai salah satu tempat pendaratan utama berperan peran penting pada kegiatan penangkapan ikan tuna di WPP 573. Menurut Hidayat \& Noegraha (2015) ikan tuna neritik dominan tertangkap oleh alat tangkap payang dengan target utama penangkapan ikan tongkol terutama jenis tongkol lisong dan tongkol krai.

Tuna neritik merupakan salah satu komoditas yang bernilai ekonomis penting dengan intensitas pendaratan hasil tangkapan yang tinggi di PPN Palabuhanratu. Meningkatnya intensitas penangkapan tuna neritik salah satunya diakibatkan oleh peningkatan upaya penangkapan dan armada kapal di PPN Palabuhanratu yang didominasi oleh kapal <10 GT (KepMen No. 107/ 2015). Menurut Hidayat \&Noegraha (2015) tuna neritik di Palabuhanratu merupakan hasil tangkapan sampingan dari penangkapan ikan cakalang. Permintaan pasar lokal yang tinggi pada komoditas ini apabila dibiarkan tanpa adanya pengelolaan yang tepat, maka dikhawatirkan akan terjadi degradasi stok dan menurut Fauzi \& Anna (2005) sumberdaya terbarukan seperti perikanan apabila dilakukan pemanfaatan secara terus menerus akan mengalami degradasi. Degradasi stok dapat diartikan sebagai penurunan kualitas dan kuantitas sumberdaya (Anna 2003). Oleh karena itu diperlukan hasil penelitian yang menggambarkan kondisi stok ikan tuna neritik sebagai dasar dalam pengelolaan dan pengambilan keputusan. Tujuan penelitian ini adalah menganalisa keberlanjutan spesies tuna neritik di perairan Palabuhanratu dengan pendekatan Productivity and Susceptibility Analysis (PSA), dan diharapkan dapat digunakan untuk mendasari pengelolaan tuna neritik di perairan Palabuhanratu.

\section{BAHAN DAN METODE Pengumpulan Data}

Penelitian mencakup pengambilan data primer dan sekunder. Data primer didapatkan secara langsung dari obyek penelitian dengan observasi, kuesioner dan wawancara kepada nelayan dan pemangku kepentingan stakeholder terkait (PPN Palabuhanratu, DKP Kab. Sukabumi, pengepul, koperasi, pedagang ikan, pedagang non ikan, dan syahbandar). Metode mendasar dengan menggunakan metode PSA adalah justifikasi dari pakar/ expert yang relevan. Justifikasi expert pada penelitian ini dilakukan untuk menentukan beberapa parameter suseptibilitas (keterancaman), sedangkan parameter produktivitas diduga dengan melalui data primer. Data primer meliputi pengukuran panjang dan bobot ikan secara langsung dan data sekunder meliputi data produksi ikan dari data statistik perikanan Pelabuhan Perikanan Nusantara (PPN) Palabuhanratu dan Dinas Kelautan dan Perikanan Kabupaten Sukabumi. Lokasi penangkapan tuna neritik yang didaratkan di PPN Palabuhanratu disajikan pada Gambar 1.

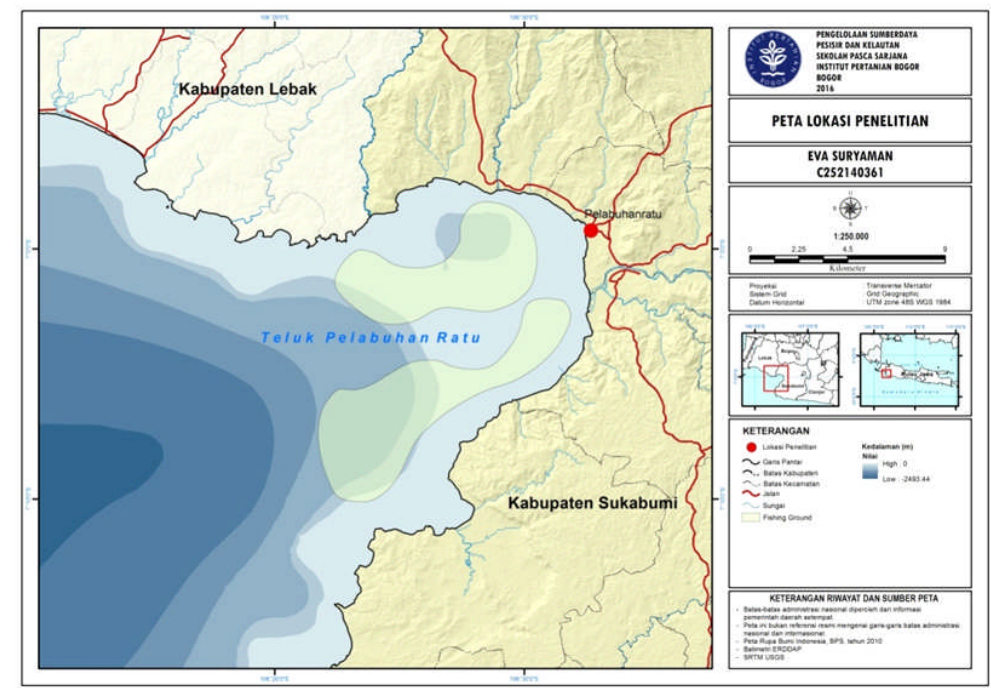

Gambar 1. Lokasi penangkapan ikan tuna neritik di perairan Palabuhanratu.

Figure 1. Fishing ground of tuna neritic in Palabuhanratu waters. 


\section{Analisis Data}

Productivity and Susceptibility Analysis (PSA) merupakan salah satu alat yang dapat digunakan untuk mengevaluasi kerentanan stok. Menurut Patrick et al. (2010) PSA merupakan metode fleksibel pengelompokan data dalam menguraikan permasalahan perikanan yang komplek yang membantu dalam menentukan solusi pengelolaan perikanan. Kebutuhan data untuk analisis PSA adalah nilai produktivitas dan suseptibilitas.

Tabel 1. Skor parameter produktivitas ${ }^{\text {a) }}$

Table 1. Score for productivity parametera)
Menurut Hobday et al. (2011) penilaian dengan analisis PSA menggunakan skor dari 1 sampai 3. Untuk parameter produktivitas (productivity) skor 1 berarti low (rendah) dan skor 3 berarti high (tinggi) yang dapat dilihat pada Tabel 1 .

Pembobotan pada parameter suseptibilitas (susceptibility) terdiri dari skor 1 berarti low (rendah) dan skor 3 berarti high (tinggi). Skor produktivitas (productivity) dan skor suseptibilitas (susceptibility) dapat dilihat pada Tabel 2.

\begin{tabular}{lccc}
\hline $\begin{array}{c}\text { Parameter } \\
\text { Productivity }\end{array}$ & $\begin{array}{c}\text { Produktivitas } \\
\text { tinggi } \\
\text { (skor =3) }\end{array}$ & $\begin{array}{c}\text { Produktivitas } \\
\text { sedang } \\
\text { (skor= 2) }\end{array}$ & $\begin{array}{c}\text { Produktivitas rendah } \\
\text { (skor= 1) }\end{array}$ \\
\hline r (intrinsic growth) & $>0,5$ & $0,16-0,5$ & $<0,16$ \\
Maximum age (tahun) & $<10$ & $10-30$ & $>30$ \\
Maximum size(cm) & $<60$ & $60-150$ & $>150$ \\
K (Growth Coefficient) & $>0,25$ & $0,15-0,25$ & $<0,15$ \\
M (Natural Mortality) & $>0,40$ & $0,20-0,40$ & $<0,20$ \\
Fecundity & $>10^{4}$ & $10^{2}-10^{3}$ & $<10^{2}$ \\
Reproductive strategyb) & Broadcast spawner & Demersal egg & Live bearer (and birds) \\
Recruitment pattern & $>75 \%$ & $10-75 \%$ & $<10 \%$ \\
Age at Maturity (tahun) & $<2$ & $2-4$ & $>4$ \\
Mean Tropic level & $<2,5$ & $2,5-3,5$ & $>3,5$ \\
\hline
\end{tabular}

a) Sumber: modifikasi Patrick etal.(2010) ; b) Hobday et al. (2011).

Tabel 2. Skor parameter susceptibilityc)

Tabel 2. Score for susceptibility parameter ${ }^{c}$

\begin{tabular}{|c|c|c|c|}
\hline $\begin{array}{c}\text { Parameter } \\
\text { Susceptibility }\end{array}$ & $\begin{array}{c}\text { Rendah } \\
\text { (low, skor=1) }\end{array}$ & $\begin{array}{c}\text { Sedang } \\
\text { (medium, skor=2) }\end{array}$ & $\begin{array}{c}\text { Tinggi } \\
\text { (high, skor }=3 \text { ) }\end{array}$ \\
\hline Area Overlap (\%) & $>25$ & $25-50$ & $>50$ \\
\hline Concentrasi geografis (\%) & $>50$ & $25-50$ & $<25$ \\
\hline Vertikal overlap (\%) & $<25$ & $25-50$ & $>50$ \\
\hline Seasonal migration & $\begin{array}{l}\text { Hasil tangkapan ikan } \\
\text { menurun }\end{array}$ & Tidak berpengaruh & $\begin{array}{l}\text { Hasil tangkapan } \\
\text { ikan meningkat }\end{array}$ \\
\hline Schooling and aggregation & $\begin{array}{l}\text { Tingkah laku ikan } \\
\text { dapat menurunkan } \\
\text { hasil tangkapan ikan. }\end{array}$ & $\begin{array}{l}\text { Tingkah laku ikan } \\
\text { dapat tidak } \\
\text { mempengaruhi hasil } \\
\text { tangkapan ikan. }\end{array}$ & $\begin{array}{l}\text { Tingkah laku ikan } \\
\text { dapat meningkatkan } \\
\text { hasil tangkapan } \\
\text { ikan. }\end{array}$ \\
\hline $\begin{array}{l}\text { Morfology characteristics } \\
\text { affecting Capture }\end{array}$ & Selektif & Tidak berpengaruh & Tidak selektif \\
\hline Desirability/Value of the Fishery & Nilai ekonomi rendah & $\begin{array}{l}\text { Nilai ekonomi } \\
\text { sedang }\end{array}$ & Ekonomis penting \\
\hline Management strategy & $\begin{array}{l}\text { Ada aturan } \\
\text { pemerintah tentang } \\
\text { pembatasan hasil } \\
\text { tangkapan ikan }\end{array}$ & $\begin{array}{l}\text { Ada aturan tentang } \\
\text { pembatasan hasil } \\
\text { tangkapan ikan di } \\
\text { masyarakat }\end{array}$ & $\begin{array}{l}\text { Tidak ada aturan } \\
\text { tentang pembatasan } \\
\text { hasil tangkapan } \\
\text { ikan. }\end{array}$ \\
\hline $\begin{array}{l}\text { Fishing Mortality (in relation to } \\
\text { M) }\end{array}$ & $<0.5$ & $0.5-1.0$ & $>1$ \\
\hline Survival after Capture & $>67 \%$ & $33 \%-67 \%$ & $<33 \%$ \\
\hline Fishery impact on habitat & $\begin{array}{l}\text { Tidak merusak } \\
\text { habitat }\end{array}$ & $\begin{array}{l}\text { Merusak habitat } \\
\text { (secara sementara) }\end{array}$ & $\begin{array}{l}\text { Merusak Habitat } \\
\text { (secara permanen) }\end{array}$ \\
\hline
\end{tabular}

c) Sumber: modifikasi Patrick et al. (2010). 
Menurut Robinson (2016) nilai produktivitas dan suseptibilitas didapatkan dari: (jumlah/bobot x skor)/ (jumlah/bobot) serta menurut Ormseth \& Paul (2011) menyatakan rumus yang digunakan dalam menghitung kerentanan (vulnerability) adalah sebagai berikut:

$v=\sqrt{(p-3)^{2}+(s-1)^{2}}$

dimana:

$\mathrm{v}=$ kerentanan

$\mathrm{p}=$ produktivitas $\mathrm{s}=$ suseptabilitas

Stok ikan dikategorikan sudah rentan mengalami overfishing di alam jika nilai kerentanannya $(\mathrm{V}) \geq 1,8$ (Patrick et al., 2010).

Kesimpulan didapat melalui penilaian setelah pengelompokan sesuai dengan skor yang ada. Adapun bobot dan kualitas parameter produktivitas (productivity) dan suseptibilitas (susceptibility) disajikan pada Tabel 3 .

Tabel 3. Bobot, nilai dan kualitas data parameter produktivitas dan susceptibilitas

Tabel 3. Weight, value and data quality for productivity and susceptibility parameter

\begin{tabular}{|c|c|}
\hline $\begin{array}{c}\text { Parameter } \\
\text { penilaian }\end{array}$ & Nilai \\
\hline Bobot nilai & $\begin{array}{l}\text { Bobot nilai menunjukan nilai kepentingan dari setiap parameter. } \\
0=\text { Tidak penting } 1=\text { Kurang penting } \\
2=\text { Penting } \quad 3=\text { Lebih penting } \\
4=\text { Sangat penting }\end{array}$ \\
\hline Atribut Skor & $\begin{array}{cl}\text { Produktivitas } & \text { Susceptabilitas } \\
1=\text { Tinggi } & 1=\text { Rendah } \\
2=\text { Sedang } & 2=\text { Sedang } \\
3=\text { Rendah } & 3=\text { Tinggi }\end{array}$ \\
\hline Kualitas Data & $\begin{array}{l}\text { Berkisar antara } 1-5 \\
\begin{array}{l}1 \text { = Data banyak dan lengkap } \\
2=\text { Data terbatas (temporal dan spasial) } \\
3=\text { Data dari genus atau family yang sama } \\
4=\text { Data baru bersifat informasi yang belum terpublikasi } \\
5=\text { Tidak ada data }\end{array}\end{array}$ \\
\hline
\end{tabular}

Setiap jenis ikan yang memperoleh skor produktivitas rendah dan skor suseptibilitas yang tinggi menunjukan ikan berada pada risiko tinggi terancam habis atau memiliki nilai kerentanan (vulnerability) yang tinggi. Sementara ikan dengan nilai produktivitas tinggi dan skor nilai suseptibilitas rendah berarti mempunyai risiko rendah untuk terancam habis atau memiliki nilai kerentanan (vulnerability) yang rendah. Unit perikanan dengan nilai suseptibilitas yang tinggi dengan nilai produktivitas yang rendah merupakan unit yang beresiko tinggi, sementara jika nilai suseptibilitas rendah dan nilai produktvitas tinggi berada pada resiko rendah (Hobday et al., 2007).

\section{HASIL DAN BAHASAN \\ Hasil}

\section{Parameter Produktivitas dan Suseptibilitas}

Parameter produktivitas dan suseptibilitas merupakan parameter yang digunakan sebagai alat ukur untuk mengetahui resiko atau kerentanan dari stok ikan tertentu terhadap tekanan penangkapan. Analisa produktivitas dan suseptibilitas merupakan salah satu yang dapat digunakan untuk mengevaluasi kerentanan stok (Triharyuni et al., 2013). Parameter produktivitas adalah parameter yang digunakan untuk melihat seberapa cepat suatu spesies dapat memulihkan diri dari dampak atau degradasi stok akibat penangkapan ikan. Hasil analisis parameter produktivitas ikan tuna neritik di perairan Palabuhanratu disajikan pada Tabel 4.

Suseptibilitas adalah menunjukkan potensi sumberdaya ikan terkena dampak aktifitas penangkapan. Hasil parameter suseptibilitas tuna neritik di perairan Palabuhanratu disajikan pada Tabel 5.

\section{Tingkat Kerentanan (Vulnerability Level)}

PSA merupakan metode yang digunakan dalam menganalisis tingkat resiko kerentanan stok ikan untuk pengelolaan perikanan yang berkelanjutan. PSA dapat digunakan untuk multispesies dengan menggunakan parameter biologi dan ekologi (Stobutzki et al., 2002, Patrcik et al., 2010). Hasil perhitungan nilai produktivitas dan suseptabilitas serta nilai kerentanan disajikan pada Tabel 6 . 
Tabel 4. Nilai parameter produktivitas ikan tuna neritik di perairan Palabuhanratu Table 4. Value of productivity parameter for neritic tuna in Palabuhanratu waters

\begin{tabular}{|c|c|c|c|c|c|c|}
\hline Parameter & Satuan & Tenggiri & Tongkol Krai & $\begin{array}{l}\text { Tongkol } \\
\text { Abu-abu }\end{array}$ & $\begin{array}{c}\text { Tongkol } \\
\text { Komo }\end{array}$ & $\begin{array}{c}\text { Tongkol } \\
\text { Lisong }\end{array}$ \\
\hline $\begin{array}{l}r \text { (intrinsic } \\
\text { growth) }\end{array}$ & $\begin{array}{l}\text { ton/ } \\
\text { tahun }\end{array}$ & $1,06^{1}$ & $0,29^{3}$ & $0,42^{1}$ & $0,12^{1}$ & $0,10^{1}$ \\
\hline Maximum age & tahun & $4,41^{2}$ & $1,67^{2}$ & $9,38^{2}$ & $2,31^{2}$ & $3,57^{2}$ \\
\hline Maximum size & $\mathrm{cm}$ & $90,77^{1}$ & $61,85^{1}$ & $49,88^{1}$ & $35,91^{1}$ & $33,92^{1}$ \\
\hline $\begin{array}{l}K \text { (growth } \\
\text { coefficient) }\end{array}$ & /tahun & $0,68^{1}$ & $1,80^{1}$ & $0,32^{1}$ & $1,30^{1}$ & $0,84^{1}$ \\
\hline $\begin{array}{l}M \text { (natural } \\
\text { mortality) }\end{array}$ & & $0,83^{1}$ & $1,74^{1}$ & $0,60^{1}$ & $1,64^{1}$ & $1,26^{1}$ \\
\hline Fecundity & butir & $\begin{array}{l}320000- \\
950000^{2}\end{array}$ & $\begin{array}{c}200000- \\
1060000^{2}\end{array}$ & $\begin{array}{l}383347- \\
3468350^{4}\end{array}$ & $\begin{array}{l}210000- \\
680000^{2}\end{array}$ & $\begin{array}{c}31000- \\
103000^{5}\end{array}$ \\
\hline Reproductive & & Partial & Partial & Partial & Partial & Partial \\
\hline strategy & & Spawner ${ }^{2}$ & Spawner ${ }^{2}$ & Spawner $^{2}$ & Spawner $^{2}$ & Spawner ${ }^{2}$ \\
\hline $\begin{array}{l}\text { Recruitment } \\
\text { pattern }\end{array}$ & $\%$ & $76,37^{6}$ & $53,3^{7}$ & $53,2^{8}$ & $19,38^{9}$ & $60^{10}$ \\
\hline $\begin{array}{l}\text { Age at } \\
\text { Maturity }\end{array}$ & tahun & $2,00^{2}$ & $0,50^{2}$ & $1,90^{2}$ & $3,00^{2}$ & $2,00^{2}$ \\
\hline $\begin{array}{l}\text { Mean Tropic } \\
\text { level }\end{array}$ & & $4,50^{2}$ & $4,40^{2}$ & $4,50^{2}$ & $4,50^{2}$ & $4,30^{2}$ \\
\hline
\end{tabular}

Tabel 5. Nilai parameter suseptibilitas ikan tuna neritik di perairan Palabuhanratu

Table 5. Value of susceptibility parameter for neritic tuna in Palabuhanratu waters

\begin{tabular}{|c|c|c|c|c|c|}
\hline Parameter & Tenggiri & Tongkol Krai & $\begin{array}{c}\text { Tongkol Abu- } \\
\text { abu }\end{array}$ & $\begin{array}{l}\text { Tongkol } \\
\text { Komo }\end{array}$ & $\begin{array}{l}\text { Tongkol } \\
\text { Lisong }\end{array}$ \\
\hline $\begin{array}{l}\text { Area Overlap } \\
(\%)\end{array}$ & $71 \%^{1)}$ & $60 \%{ }^{11)}$ & $60 \%^{11}$ & $71 \%{ }^{1)}$ & $71 \% 1)$ \\
\hline $\begin{array}{l}\text { Concentrationg } \\
\text { eographic }(\%)\end{array}$ & $60 \%{ }^{1)}$ & $70 \%{ }^{1)}$ & $60 \%{ }^{1)}$ & $65 \%^{1)}$ & $60 \%{ }^{1)}$ \\
\hline $\begin{array}{l}\text { Vertical overlap } \\
(\%)\end{array}$ & $42 \%{ }^{1)}$ & $50 \%{ }^{1)}$ & $50 \%{ }^{1)}$ & $57 \%^{1)}$ & $57 \%{ }^{1)}$ \\
\hline $\begin{array}{l}\text { Seasonal } \\
\text { migration }\end{array}$ & $1^{1)}$ & $1^{1)}$ & $1^{1)}$ & $1^{1)}$ & $1^{1)}$ \\
\hline $\begin{array}{l}\text { Schooling and } \\
\text { aggregation }\end{array}$ & $2^{1)}$ & $2^{1)}$ & $2^{1)}$ & $2^{1)}$ & $2^{1)}$ \\
\hline $\begin{array}{l}\text { Morfology } \\
\text { Affecting } \\
\text { Capture }\end{array}$ & Tidak selektif & selektif & selektif & Tidak selektif & Tidak selektif \\
\hline $\begin{array}{l}\text { Desirability/Valu } \\
\text { e of the Fishery }\end{array}$ & $\begin{array}{l}\text { Rp. } 50000 / \mathrm{kg} \\
\text { (harga tinggi) }\end{array}$ & $\begin{array}{l}\text { Rp. } 25000 / \mathrm{kg} \\
\text { (harga tinggi) }\end{array}$ & $\begin{array}{c}\text { Rp. } 18000 / \mathrm{kg} \\
\text { (harga }^{1} \\
\text { sedang) }^{1}\end{array}$ & $\begin{array}{l}\text { Rp. } 20000 \text { / kg } \\
\text { (harga } \\
\text { sedang) }\end{array}$ & $\begin{array}{l}\text { Rp. } 14000 / \mathrm{kg} \\
\text { (harga rendah) } \\
1\end{array}$ \\
\hline $\begin{array}{l}\text { Management } \\
\text { strategy }\end{array}$ & $3^{1}$ & $3^{1}$ & $3^{1}$ & $3^{1}$ & $3^{1}$ \\
\hline $\begin{array}{l}\text { Fishing } \\
\text { Mortality (in } \\
\text { relation to } M \text { ) = } \\
F / M\end{array}$ & $1.08^{1}$ & $1.72^{1}$ & $0.72^{1}$ & $1.52^{1}$ & $1.17^{1}$ \\
\hline $\begin{array}{l}\text { Survival after } \\
\text { Capture (\%) }\end{array}$ & $68 \% 1$ & $20 \% 1$ & $68 \% 1$ & $30 \% 1$ & $30 \% 1$ \\
\hline $\begin{array}{l}\text { Fishery impact } \\
\text { on habitat }\end{array}$ & $\begin{array}{c}\text { Dampak } \\
\text { terhadap } \\
\text { habitatnya } \\
\text { minim }^{1}\end{array}$ & $\begin{array}{c}\text { Dampak } \\
\text { terhadap } \\
\text { habitatnya } \\
\text { minim }^{1}\end{array}$ & $\begin{array}{c}\text { Dampak } \\
\text { terhadap } \\
\text { habitatnya } \\
\text { minim }^{1}\end{array}$ & $\begin{array}{c}\text { Dampak } \\
\text { terhadap } \\
\text { habitatnya } \\
\text { minim }^{1}\end{array}$ & $\begin{array}{c}\text { Dampak } \\
\text { terhadap } \\
\text { habitatnya } \\
\text { minim }^{1}\end{array}$ \\
\hline
\end{tabular}

Keterangan: 1. Ikan bermigrasi sehingga berpengaruh terhadap hasil tangkapan ikan;

2. Tingkah laku ikan dapat meningkatkan hasil tangkapan ikan;

3. Belum ada aturan tentang pembatasan hasil tangkapan ikan

Sumber: ${ }^{1)}$ data primer diperoleh dari analisis data, wawancara dengan nelayan dan stakeholder. 
Tabel 6. Nilai kerentanan tuna neritik di Perairan Palabuhanratu

Table 6. Value of vulnerability for neritic tuna in Palabuhanratu waters

\begin{tabular}{clccc}
\hline No & \multicolumn{1}{c}{ Nama Ikan } & Nilai Produktivitas & Nilai Suseptabilitas & Nilai Kerentanan \\
\hline 1 & Tenggiri & 2,60 & 2,18 & 1,25 \\
2 & Tongkol Krai & 2,50 & 2,27 & 1,37 \\
3 & Tongkol Abu-Abu & 2,60 & 1,82 & 0,91 \\
4 & Tongkol Komo & 2,40 & 2,36 & 1,49 \\
5 & Tongkol Lisong & 2,40 & 2,27 & 1,41 \\
\hline
\end{tabular}

Selain indeks kerentanan, analisis produktivitas dan suseptibilitas menggunakan software PSA yang dikembangkan oleh NOAA (National Oceanic and Atmospheric Administration) menghasilkan grafik

yang menghubungkan parameter produktivitas dan suseptibilitas. Hasil analisis kerentanan ikan dengan software PSA di sajikan pada Gambar 3.

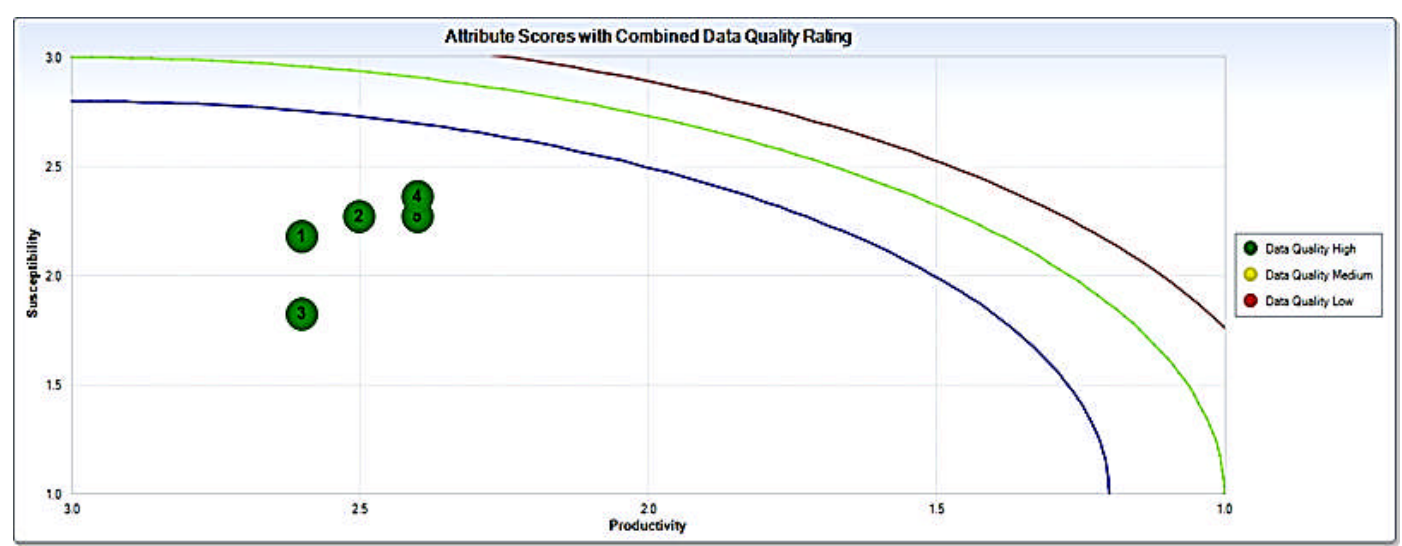

Keterangan: 1. Tenggiri; 2. Tongkol krai; 3. Tongkol abu-abu; 4. Tongkol komo; 5. Tongkol lisong Gambar 3. Grafik analisis produktivitas dan suseptibilitas.

Figure 3. Productivity and susceptibility analysis graph.

Data yang digunakan sebagian besar adalah data primer yang di peroleh langsung dari hasil pengamatan di lokasi penelitian. Garis warna merah yang membujur menunjukkan bahwa ikan memiliki tingkat kerentanan tinggi. Kerentanan sedang ditunjukkan pada area garis warna hijau membujur. Adapun garis warna biru yang membujur menunjukkan daerah kerentanan yang rendah. Kerentanan ikan tuna neritik tersebar dibawah garis warna biru, hal ini menunjukkan tingkat kerentanan tuna neritik di Perairan Palabuhanratu masih rendah. Kerentanan yang tinggi bisa terjadi apabila ikan memiliki produktivitas yang rendah dan suseptibilitas yang tinggi.

\section{Bahasan}

Terdapat dua jenis sheerfish dan empat jenis tuna neritik yang didaratkan di PPN Palabuhanratu yaitu ikan tenggiri, tongkol krai, tongkol komo, dan tongkol lisong. Perairan Palabuhanratu termasuk dalam Wilayah Pengelolaan Perikanan 573 (WPPNRI 573). Berdasarkan Keputusan Menteri Kelautan dan Perikanan No. 47/MEN/2016 tingkat pemanfaatan ikan pelagis besar (non tuna cakalang) termasuk didalamnya adalah tuna neritik yaitu 0.78 dengan status pemanfaatan fully-exploited. Kondisi pemanfaatan eksploitasi ikan pada KEPMEN No.47/MEN/2016 diduga berdasarkan data produksi pada kondisi aktual dan MSY (Maximum Sustainable Yield). Kondisi eksploitasi sumberdaya ikan secara kualitatif juga dapat diduga berdasarkan nilai kerentanannya (Patrcik et al., 2010). Productivity and Susceptibility Analysis (PSA) merupakan salah satu alat yang dapat digunakan untuk mengevaluasi kerentanan stok (bukan stok)

Analisis PSA dilakukan dengan menggunakan dua indikator yaitu produktivitas dan suseptibilitas. Hasil analisis produktivitas menunjukkan bahwa pertumbuhan ikan tenggiri tertinggi dibandingkan ikan lainnya yaitu 1,06 ton per tahun dengan umur maksimum (life span) 4,41 tahun. Laju pertumbuhan intrinsik tongkol krai relatif lebih kecil yaitu 0,29 per tahun dan hidup sampai 1,67 tahun, tongkol abu-abu 0,12 per tahun dengan jangka hidup lebih lama yaitu 9,38 , tongkol komo sebesar 0,12 per tahun dengan jangka hidup 2,31 tahun, dan tongkol lisong memiliki laju pertumbuhan intrinsik terkecil sebesar 0,10 per 
tahun dengan jangka hidup 3,57 tahun. Laju pertumbuhan intrinsik ( $r$ ) ikan diduga dengan metode Algoritma Fox berdasarkan data produksi dan upaya penangkapan (Zulbainarni et al., 2011). Berdasarkan laju mortalitas alaminya $(\mathrm{M})$ tuna neritik berkisar antara 0,83-1,74. Ikan tongkol krai memiliki tingkat kematian alami lebih besar yaitu 1,74. Menurut Pauly (1984) dan Catalano \& Allen (2010) faktor yang mempengaruhi nilai $M$ adalah suhu rata-rata perairan dan laju pertumbuhan $(k)$. Nilai $M$ tuna neritik di Perairan Palabahanratu tergolong tinggi yang menurut klasifikasi dari Beverton \& Holt (1959) in Sparre \& Venema (1999) yang menyatakan nilai M yang tergolong tinggi berkisar antara 1,5-2,5.

Nilai mean trophic levelikan tenggiri, tongkol krai, tongkol abu-abu, tongkol komo, dan tongkol lisong memiliki nilai yang tidak terlalu berbeda. Ikan-ikan tersebut termasuk dalam jenjang trofik level ke empat yaitu kelompok ikan karnivora, yang memiliki nilai trofik level 3,7-4,5 (Stergiou \& Karpouzi,2002: Allain et al., 2012).Hal ini menunjukan bahwa ikan tuna neritik termasuk dalam jenjang trofik level yang tinggi, dengan produktivitas yang rendah (Hobday et al., 2011)

Nilai kerentanan tuna neritik berturut-turut ikan tenggiri 1,25 , tongkol krai 1,37 , tongkol abu-abu 0,91 , tongkol komo 1,49, dan tongkol lisong 1,41.Berdasarkan nilai kerentanan tersebut menunjukan bahwa tingkat resiko kerentanan dari tekanan penangkapan ikan saat ini masih rendah karena nilainya dibawah 1,8 (Patrick et al., 2010). Nilai productivity $(p)$ ikan tuna neritic lebih besar dibandingkan nilai susceptability (s), hal ini menunjukan tingkat produktivitas tuna neritik lebih besar daripada tingkat suseptibilitasnya. Nilai produktivitas yang disebabkan beberapa parameter produktivitas ikan memiliki skor yang tinggi seperti laju pertumbuhan ikan (k) yaitu berkisar 0,32-1,80. Hal ini menunjukan bahwa kondisi Perairan Palabuhanratu cocok dan masih bagus untuk pertumbuhan ikan tuna neritik. Pertumbuhan yang relatif cepat mengindikasikan kelimpahan makanan dan kondisi lingkungan yang cocok (Hernandez \& Seijo, 2003). Menururt Wahyudin (2011) secara keseluruhan kondisi perairan Palabuhanratu tergolong bagus, kecuali beberapa lokasi yang kondisi perairanya tergolong tercemar yaitu sekitar PLTU.

Menurut Zhou et al. (2011) meskipun hasil analisis PSA berada dibawah nilai kerentanannya, pengelolaan sumber daya ikan harus tetap dilakukan untuk menjaga keberlanjutan stok ikan dalam jangka waktu yang lama. Salah satunya dengan menerapkan prinsip-prinsip pengelolaan perikanan berkelanjutan (pengelolaan input dan output). Hasil analisis PSA bisa digunakan untuk melakukan kajian resiko yang pada umumnya dapat untuk membantu pengelolaan perikanan (Francis \& Shotten, 1997 dalam Arizabalaga et al., 2011). Astles (2008) memberikan sebuah review kajian resiko dalam bidang kelautan dan perikanan serta elemen yang dibutuhkan untuk memperkirakan risiko ekologis. Kajian resiko ekologi (Ecological Risk Assessment/ERA) dapat menyediakan metodologi yang transparan dalam penilaian risiko yang lebih kompleks dan atau dalam mengambil tindakan pengelolaan untuk berbagai spesies dalam perikanan (Arizabalaga et al., 2011).

Kerentanan yang tinggi bisa terjadi apabila ikan memiliki produktivitas yang rendah dan suseptibilitas yang tinggi. Ikan tongkol komo memiliki nilai susceptibility yang tertinggi sehingga memiliki indeks kerentanan yang tertinggi dan memiliki resiko yang tinggi dari kegiatan penangkapan. Hal ini disebabkan ikan tongkol komo memiliki pola rekrutmen atau penambahan individu baru yang terendah dengan nilai mortalitas alami yang tinggi. Sementara itu ikan tongkol abu abu dan tenggiri terlihat memiliki nilai kerentanan yang terendah, hal ini disebabkan ikan tenggiri dan tongkol abu abu memiliki produktivitas yang tinggi dengan nilai suseptibilitas yang rendah.

\section{KESIMPULAN}

Tingkat kerentanan tuna neritik di Perairan Palabuhanratu berdasarkan analisis PSA tergolong rendah. Nilai productivity $(p)$ ikan tuna neritik lebih besar dibandingkan nilai susceptability (s), hal ini menunjukan aktivitas penangkapan masih dapat ditingkatkan terutama untuk spesies tuna neritik yang nilai kerentanan rendah yaitu ikan tenggiri dan tongkol abu-abu.

\section{PERSANTUNAN}

Penulis mengucapkan terimakasih kepada Badan Pengembangan Sumber Daya Manusia dan Pemberdayaan Masyarakat Kelautan dan Perikanan (BPSDM KP), Kementerian Kelautan dan Perikanan atas biaya pendidikan penulis pada program Magister (S2) program studi Pengelolaan Sumberdaya Pesisir dan Lautan, Institut Pertanian Bogor dan Pelabuhan Perikanan Nusantara Palabuhanratu atas bantuan yang diberikan pada saat penelitian. 


\section{DAFTAR PUSTAKA}

Abdussamad, E. M., Said K. P., Ghosh, S., Rohit, P., Joshi, K. K., Manojkumar, B., \& Bineesh, K. K. (2012). Fishery, biology and population characteristics of longtail tuna, Thunnus tonggol (Bleeker, 1851) caught along the Indian coast. Indian Journal Fish, 59 (2), 7-16. Diakses dari http://epubs.icar.org.in/ejournal/index.php/IJF/ article/down load/15407/10467.

Allain, V., Shane, P. G., Jeff, P., \& Simon, N. (2012). Ecosystem indicator trends and result from ecopath simulation. Diakses dari https:// www.wcpfc.int/system/files/EB-IP-11-WCPOEcosystem-Indicator-Trends-and-ResultsEcopath-Simulations.pdf.

Anna, S. (2003). Model embedded dinamik ekonomi interaksi perikanan-pencemaran [disertasi]. Institut Pertanian Bogor.

Arizabalaga, Bruyn, H.P., Diaz, G.A., Murua, H., Chavance, P., Molina, A.D., Gaertner, D.J., Ariz, Ruiz, J., \& Kell, L.T. (2011). Productivity and susceptibility analysis for species caught in Atlantic tuna fisheries. Aquat. Living Resour. 24,112.

Astles, K.L. (2008). A systematic approach to estimating ecological risks in marine fisheries. CABI Reviews: Perspectives in Agriculture, Veterinary Science, Nutrition and Natural Resources. 3(045): 16 p. doi:10.1079/ PAVSNNR 2008304.

Catalano, M.J., \& Allen, M.S. (2010). A size-angage-structured model to estimate fish recruitment, growth, mortality, and gear selectivity. Fisheries Research. 105, 38-45.

Fauzi, \& Anna, S. (2005). Permodelan sumberdaya perikanan dan kelautan untuk analisis kebijakan (p. 343). Jakarta: PT. Gramedia Pustaka Utama.
Griffiths, S. P. (2010). Stock assessment and efficacy of size limitson longtail tuna (Thunnus tonggol) caught in Australian waters. Fisheries Research, 102(3),248-257. doi:10.1016/ j.fishres.2009.12.004.

Hernandez, A., \& Seijo, J.C. (2003). Spatial distribution analysis of red grouper (Epinephelus morio) fishery in Yucatan Mexico. Fisheries Research.63, 135-141.

Hidayat, T., \& Noegraha, T. (2015). Pemanfaatan Tuna Neritik Dengan Alat Tangkap Payang Di Perairan Palabuhanratu Samudera Hindia. Dalam WWF: Simposium Nasional Pengelolaan Perikanan Tuna Berkelanjutan (pp. VI-173-179). Bali, ID: WWF-Indonesia.

Hobday, A. J., Smith, A., Webb, H., Daley, R., Wayte, S., Bulman,...\& Walker, T. (2007). Ecological Risk Assessment for the Effects of Fishing: Methodology. Diakses dari https:// p u b I i c a tions. cs i ro.a u/rpr/ download?pid=changeme:3904 \& dsid=DS1.

Hobday, A. J., Smith, A. D. M., Stobutzki, I. C., Bulman, C., Daley, R., Dambacher, J. M.,...\& Zhou, S. (2011). Ecological risk assessment for the effects of fishing. Fisheries Research, 108 (2-3), 372-384. doi:10.1016/ j.fishres.2011.01.013.

Jatmiko, I., Sulistyaningsih, R. K., \& Setyadji, B. (2013). Study on population parameters of kawakawa, Euthynnus affinis (Cantor 1849), in Indian Ocean (a case study in Northwest Sumatra IFMA 572). In Third Working Party on Neritic Tunas (pp. 1-9). Bali, ID: IOTC-2013WPNT03-20. Diakses dari http://www.iotc.org/ sites/default/files/documents/2013/06/IOTC2013 - W P N T $03-20 \% 20$ \%20Kawakawa\%20population\%20parameters_0.pdf.

Jasmine, S., Rohit, P., Abdussamad, E. M., Said Koya K. P., Joshi, K. K., Kemparaju,S.,...\& Sebastine, M. (2013). Biology and fishery of the 
bullet tuna, Auxis rochei (Risso, 1810) in Indian waters. Indian Journal Fisheries, 60(2), 13-20. Diakses dari http://eprints.cmfri.org.in/9505/1/2S_Jasmine.pdf.

Kekenusa, J. S., Rondonuwu, S. B., Paendong, M. S., \& Weku, W. Ch. D. (2014). Determinating the utilization status and management scenario of Bonito (Auxis rochei) catching in Talaud Waters North Sulawesi. Research Journal

of

Mathematical and Statistical Sciences, 2(11), 1-8. Diakses dari http://www.isca.in/ MATH_SCI/Archive/v2/i11/1.ISCA-RJMSS2014-051.pdf.

Keputusan Kementerian Kelautan dan Perikanan. (2015). Keputusan Menteri Kelautan Dan Perikanan No.107 Tahun 2015 tentang Rencana Pengelolaan Perikanan Tuna Cakalang Tongkol.

Naderi, R. A. (2016). Assessment of social consideration on Neritic tuna in Iran fishery management. Working party on Neritic Tuna (WPNT06), IOTC-2016-WPNT06-12 Rev_1.

Noegroho, T., \& Hidayat, T. (2014). Dinamika Populasi Ikan Tenggiri (Scomberomorus commerson) di Perairan Teluk Kwandang, Laut Sulawesi. J.Lit.Perik.ind, 20(4), 251-258.

Ormseth, O. A., \& Paul, D. S. (2011). An assessment of vulnerability in Alaska groundfish.Fisheries Research, 112, 127-133. doi:10.1016/j.fishres.2011.02.010.

Patrick, W. S., Spencer, P., Link, J., Cope, J., Field, J., Kobayashi, D.,...\& Overholtz, W. (2010). Using Productivity and Susceptibility Indices to Asses the Vulnerability of United States Fish Stock to Overfishing. Fishery Bulletin, 108, 305322. Diakses dari http://aquaticcommons.org/ 8747/1/patrick_Fish_Bull_2010.pdf.
Pauly D. (1984). Some Simple Methods for Tropical Fish Stock. FAO Fish. Tech. Pap. (243): 52 pp. French and Spanish.

Robinson, J. (2016).A productivity and susceptibility analysis for neritic tuna species. In International Organization Tuna Commission, Reportof the 6th Working Party on Neritic Tunas.Mahe, Seychelles, 21-24 June 2016. Diakses dari http:/ /www.iotc.org/sites/default/files/documents/ 2016/08/IOTC-2016-WPNT06-RE__FINAL_DO_NOT_MODIFY.pdf.

Sparre, P., \& Venema, S.C. (1999). Introduksi Pengkajian Stok Ikan Tropis. Jakarta: Pusat Penelitian dan Pengembangan Perikanan.

Stergiou, K. I., \& Karpouzi, V. S. (2002). Feeding habits and trophic levels of Mediterranean fish. Reviews in Fish Biology and Fisheries, 11(3), 217-254. doi:10.1023/ A:1020556722822.

Stobutzki, I. C., Miller, M. J., Heales, D. S., \& Brewer, D. T. (2002). Sustainability of elasmobranchs caught as bycatch in a tropical prawn (shrimp) trawl fishery. Fishery Bulletin. 100, 800821. Diakses dari http://aquaticcommons.org/ 15251/1/13stobut.pdf.

Triharyuni, S., Hartati, S.T., Anggawangsa, R.F. (2013). Produktivitas dan kerentanan ikan kurisi (Nemipterus Spp) hasil tangkapan cantang di Laut Jawa. J.Lit.Perik.ind, 19(4), 213-220.

Uchida, R. N. (1981). Synopsis ofBiological Data on Frigate Tuna, Auxis thazard, and Bullet Tuna, A. Rochei. Dalam National Oceanic and Atmospheric AdministrationTechnical Report NMFS Circular 436 (pp. 1-63). United State, US: FAO Fisheries Synopsis No. 124. Diakses dari http:/ /www.fao.org/docrep/017/ap931e/ap931e.pdf 
Wahyudin, Y. (2011). Karakteristik sumberdaya pesisir dan laut kawasan Teluk Palabuhanratu, Kabupaten Sukabumi, Jawa Barat. Bonorowo Wetlands, 1,19-23.

Zulbainarni, N., Tambunan, M., Syaukat, Y., Fahrudin, A. (2011). Model bioekonomi eksploitasi multispesies sumber daya perikanan pelagis di Perairan Selat Bali. Marine Fisheries. 2(2), 141-154.
Zhou, S., Anthony, D. M. S., \& Mike, F. (2011). Quantitative ecological risk assessment for fishing effects on diverse data poor non target species in multisector and multigear fishery. Fisheries Research, 112(3), 168-178. doi:10.1016/ j.fishres.2010.09.028. 